BMJ Paediatrics Open

\title{
Educational intervention to improve intravenous cannulation skills in paediatric nurses using low-fidelity simulation: Indian experience
}

\author{
Vallaree Anant Morgaonkar, ${ }^{1}$ Binoy Viresh Shah, ${ }^{1}$ \\ Somashekhar Marutirao Nimbalkar, ${ }^{1,2}$ Ajay Gajanan Phatak, ${ }^{2}$ Dipen Vasudev Patel, ${ }^{1}$ \\ Archana Somashekhar Nimbalkar ${ }^{3}$
}

To cite: Morgaonkar VA, Shah BV, Nimbalkar SM, et al. Educational intervention to improve intravenous cannulation skills in paediatric nurses using low-fidelity simulation: Indian experience. BMJ Paediatrics Open 2017;1:e000148. doi:10.1136/ bmjpo-2017-000148

- Additional material is published online only. To view please visit the journal online (http://dx.doi.org/10.1136/ bmjpo-2017-000148).

VAM and SMN contributed equally.

Received 31 May 2017 Revised 27 November 2017 Accepted 4 December 2017

\section{(a) CrossMark}

${ }^{1}$ Department of Pediatrics, Pramukhswami Medical College Karamsad, Gujarat, India ${ }^{2}$ Central Research Services, Charutar Arogya Mandal, Karamsad, Gujarat, India ${ }^{3}$ Department of Physiology, Pramukhswami Medical College, Karamsad, Gujarat, India

Correspondence to Professor Somashekhar Marutirao Nimbalkar, Department of Pediatrics Pramukhswami Medical College Karamsad Gujarat India ; somu somu@yahoo.com

\section{ABSTRACT}

Introduction Inserting, monitoring and maintaining intravenous access are essential components of nursing. We evaluated simulation training on a manikin to improve cannulation skills.

Methods Nursing staff managing paediatric patients were asked to cannulate NITA Newborn-1800 manikin before and after appropriate training. Skills were assessed by a single assessor using an objective structured clinical examination (OSCE) checklist. Four steps were identified as critical. A score of $8 / 10(80 \%)$ was considered satisfactory. Knowledge was assessed by 10 questions. A training module consisting of theoretical aspects, PowerPoint presentations, videos and hands on training over a manikin was conducted. Post-training assessment was done 1 week later.

Results Seventy-five (80.6\%) nurses who completed preassessments and postassessments were assessed for paired comparisons of knowledge and skill. The majority of the nurses were females, had contractual appointment, were in their early career phase and from the paediatric wards. The mean (SD) post-training knowledge score was greater vis-a-vis pretraining score $(7.52$ (1.58) vs 5.32 (1.57), $P<0.001)$. A similar result was observed for total OSCE scores (9.22 (0.66) vs 7.91 (1.11), $\mathrm{P}<0.001)$. Significantly higher proportion of participants exhibited intravenous cannulation satisfactorily after the training vis-a-vis pretraining assessment (69 (92\%) vs $36(48 \%)$ $\mathrm{P}<0.001$ )

Conclusion Training using manikin showed improvement in post-training score of intravenous cannulation skill of paediatric nurses; however, this finding needs further confirmation by a randomised control trial, as our study does not have a control group.

\section{INTRODUCTION}

Paediatric nurses are often required to place intravenous lines in neonates and children as part of the routine care. Cannulation of a vein is one of the most important procedures that paediatric nurses need to perform with precision and minimal discomfort to the children. Cannulation not only involves

\section{What is already known on this topic?}

Simulation improves task training in healthcare personnel. Simulation based training is recommended by most agencies related to health.

\section{What this study hopes to add?}

Training using low-fidelity simulation may improve intravenous cannulation skills of paediatric nurses.

placing the intravenous cannulas at an appropriate location but also requires the nurses to monitor and maintain access to the circulatory system. ${ }^{1}$

Nurses need to undergo training (cognitive and psychomotor) and supervised practice to be proficient in the skill of intravenous cannulation. The skill of intravenous cannulation must be practised regularly to maintain a high level of competency. ${ }^{2}$ This is important to gain quick and efficient intravenous access in paediatric populations when required. Children may have small sized and fragile veins and may not cooperate during cannulation due to fear-making it more difficult than in adults. There have been studies about cannulation skills of nurses in adults, but very little data is available in paediatric and neonatal patients. The high success rates of nurses who were evaluated have been attributed to the frequent performance of intravenous cannulation in the adult population. ${ }^{3}$ Assessment of paediatric intravenous cannulation skills would help highlight the areas for improvement and plan further training for the nurses that is targeted and focused.

There are different ways in which intravenous cannulation skills could be taught and evaluated. In the Indian setup, the traditional way of training has been by practice on actual 
patients under supervision of a senior nurse/doctor, after an initial period of observation and evaluation of knowledge regarding cannulation. This method, though effective, is more of an opportunistic learning, and uniform attainment of skills cannot be guaranteed. While training methodologies have remained same over time, there has been rapid advancement in intravenous cannulation over the previous decades with the equipment improving from hypodermic needles to scalp veins to intravenous cannulas that are currently being used across India. Widespread dissatisfaction with the provided education has been reported in the pre-internet era. ${ }^{4}$ The current era has many websites which do provide guidelines, reports and videos which can facilitate self-learning. However, supervised learning may be more appropriate as one of the main responsibilities of a nurse is safety of the patient to whom she is providing care. ${ }^{5}$

This can be achieved by detailed planning of training by experts who have profound understanding of the techniques and associated risks involved, while the therapy itself is empowering to the nurse.$^{6}$ Education in evidence-based care followed by routine practice in wards provides nurses the opportunity to improve their ability to use cognitive knowledge in the clinical settings. ${ }^{7}$ In the end, the care of the patient before and after the procedure and satisfactory maintenance of the intravenous line rests with a nurse. ${ }^{8}$ A nurse has to be aware of the various complications such as thrombophlebitis, catheter embolism, bleeding, nerve, tendon or ligament damage, needle stick injuries and sepsis. ${ }^{9}$

At the study site, the nursing profession has a high turnover rate with new nurses joining every year. The composition of the nursing staff is of variable experience across different departments. A module was developed and tested to train nurses in the paediatric intravenous cannulation skill.

We developed and tested a module to train the nurses in paediatric cannulation using an infant manikin and subsequently assessed the impact of the training.

\section{MATERIALS AND METHODS Study settings}

Shree Krishna Hospital, Karamsad, is a tertiary care teaching hospital in rural Gujarat with recruitment of nurses occurring throughout the year due to a high attrition rate. Most nurses are trained as general nurse midwifery (GNM) or equivalent diploma, with very few possessing a graduate degree in nursing. Nurses from neonatal intensive care unit (NICU), paediatric intensive care unit (PICU), paediatric ward, postnatal gynaecology ward, special bed unit (SBU) (private sharing rooms) and privilege gold ward (private single rooms) were included in the training sessions.

\section{Study design}

We conducted an interventional study to assess knowledge and skills of nurses regarding intravenous cannulation before and after training.

\section{Sample size}

In the absence of any background data, moderate effect size of 0.40 was considered for sample size calculation. A sample of size 68 was required to detect effect size of 0.4 (related to skills score) at $5 \%$ level of significance with $90 \%$ power. However, the authors believed that it was unethical to select some nurses for the training and exclude the others. The authors also felt that it was a good opportunity to train all nurses uniformly while conducting the study. Hence, all the 93 nurses eligible for the training were included in the hope that we would have about 70-75 nurses completing both preintervention and postintervention assessments.

\section{Training module}

The nurses were trained on a newborn manikin to improve psychomotor skills while knowledge was shared by interactive lectures.

Nurses were trained in batches of 20-25 with each training session lasting 4 hours.

Each session consisted of a pretraining assessment of knowledge and skills and an interactive lecture for knowledge followed by hands-on training on manikins for skills in a closed group (5-6 per group). NITA Newborn1800 manikin was used for training and assessment. The sequence of training session was as follows.

1. Assessment of knowledge using multiple choice questions (MCQs) (see online Supplementary file 1),

2. Assessment of intravenous cannulation skills using objective structured clinical examination (OSCE) checklist, on a manikin.

3. Actual training by investigators using a training module consisting of PowerPoint presentations, videos and hands-on training on a manikin and finally a discussion with a group of 20-25 nurses on the theoretical aspects of intravenous cannulation. The discussion contained theoretical as well as practical aspects and was active in nature.

4. Post-training assessment was done 1 week later using OSCE and a manikin for assessment of skills and MCQs for assessment of knowledge.

The knowledge questionnaire (MCQ) was prepared based on the information provided in interactive lectures in order to assess the effect of training by comparing the knowledge before and after the training.

Intravenous cannulation skills in all nurses were assessed by single assessor using OSCE checklist both before and after training. Participants were graded on a scale of $0-10$ depending on the accuracy of steps performed.

Using the guidelines of Integrated Procedural Performance Instrument (IPPI $)^{10}$ and some other available checklists for intravenous cannulation in adults, ${ }^{11} 12$ a checklist was prepared and consensually validated by a senior anaesthesiologist for its use in our skill lab for undergraduate students. The checklist was contextually modified and consensually validated among four neonatologists and two senior nursing incharge. 
Four out of 12 steps were identified as 'critical' by all investigators after reviewing similar checklists used in adults. Participants scoring greater than $80 \%$ and performing all critical steps correctly were considered to possess satisfactory skill.

\section{Statistical analysis}

Descriptive statistics were used to describe baseline characteristics of the study population. The impact of the training was assessed using paired sample t-test and test of difference between proportions depending on the nature of variables involved. The analysis was done using STATA V.14.2.

\section{RESULTS}

A total of 93 nurses providing care mainly to infants were invited to participate in the training. Seventy-nine $(85 \%)$ nurses appeared for the pretraining assessment followed by training. Four nurses could not attend post-training assessment (one nurse went on a maternity leave, one nurse was admitted to the hospital for typhoid and two nurses were posted in the peripheral centres for a month during the post-training assessment). Thus, 75 (81\%) nurses completed both the preassessment and postassessment and only these records were used for paired comparisons of knowledge and skill.

The majority of the participating nurses were females, contractual workers, in their early career and from paediatric wards. The mean (SD) income of the nurses was 17062 rupees (9105) (IQR 10000,24000 ). Only one nurse had a graduate degree (BSc) in nursing (table 1).

At baseline, significantly higher proportion of NICU nurses $(73 \%)$ performed intravenous cannulation satisfactorily as compared with other departments $(\mathrm{P}=0.02$, Fisher's exact test). The mean (SD) knowledge score was 5.29 (1.65). Although low, it was similar across departments except SBU nurses with mean (SD) score of 3.44 (1.51). Education, experience and appointment type were not significantly associated with knowledge score or intravenous cannulation skills (table 2).

The mean (SD) post-training knowledge score was significantly greater compared with the pretraining score (7.52 (1.58) vs 5.32 (1.57), $\mathrm{P}<0.001$ ) (figure 1 , table 3 ). The mean (SD) post-training OSCE score was significantly greater compared with the pretraining score (9.22 (0.66) vs 7.91 (1.11), $\mathrm{P}<0.001)$. A significant proportion of participants exhibited intravenous cannulation satisfactorily after the training compared with pretraining assessment (69 $(92 \%)$ vs $36(48 \%), \mathrm{P}<0.001)$ (table 4$)$. Out of the six participants who could not exhibit the skill satisfactorily after the training, three failed in both the criteria (attaining 80\% total score and performing all critical steps), while three failed in performing all critical steps despite attaining a passing score. In the pretraining assessment, about one-fifth (7 out of 36) participants failed in performing all critical steps despite attaining a passing score. Surprisingly, one participant who exhibited
Table 1 Sociodemographic profile of the participants

Frequency

Characteristics

(\%), $n=79$

\begin{tabular}{lc}
\hline Gender & $5(6)$ \\
\hline Male & $74(94)$ \\
\hline Female & \\
\hline Education & $61(77)$ \\
\hline General nursing and midwifery & $7(9)$ \\
\hline $\begin{array}{l}\text { Diploma-general nursing and } \\
\text { midwifery }\end{array}$ & $6(8)$ \\
\hline Registered nurse registered midwife & $4(5)$ \\
\hline Auxiliary nurse midwifery & $1(1)$ \\
\hline BSc (Nursing) & \\
\hline Appointment type & $64(81)$ \\
\hline Contractual & $15(19)$ \\
\hline Permanent & \\
\hline Posting & \\
\hline Paediatric wards & $22(28)$ \\
\hline Neonatal intensive care unit & $9(11)$ \\
\hline Paediatric intensive care unit & $8(10)$ \\
\hline Paediatric ward & $6(8)$ \\
\hline Cardiac intensive care unit & $17(22)$ \\
\hline Gynaecology ward & $8(10)$ \\
\hline Privilege gold & $9(11)$ \\
\hline Special bed unit & $17238(9181)$ \\
\hline Experience & $(10000,24000)$ \\
\hline 0-5years & \\
\hline 6-10years & \\
\hline 11-15years & $15(15)$ \\
\hline Mean (SD) (IQR) & $23(30)$ \\
\hline Income (per month in Indian Rupees) & \\
\hline Mean (SD) (IQR) & \\
\hline
\end{tabular}

the skill satisfactorily in the pretraining assessment failed to exhibit the same in the post-training assessment again due to failure in performing all the critical steps.

\section{DISCUSSION}

Training showed improvement in post-training score of intravenous cannulation skill of paediatric nurses; however, this needs further confirmation by a randomised control trial, as our study does not have a control group. 


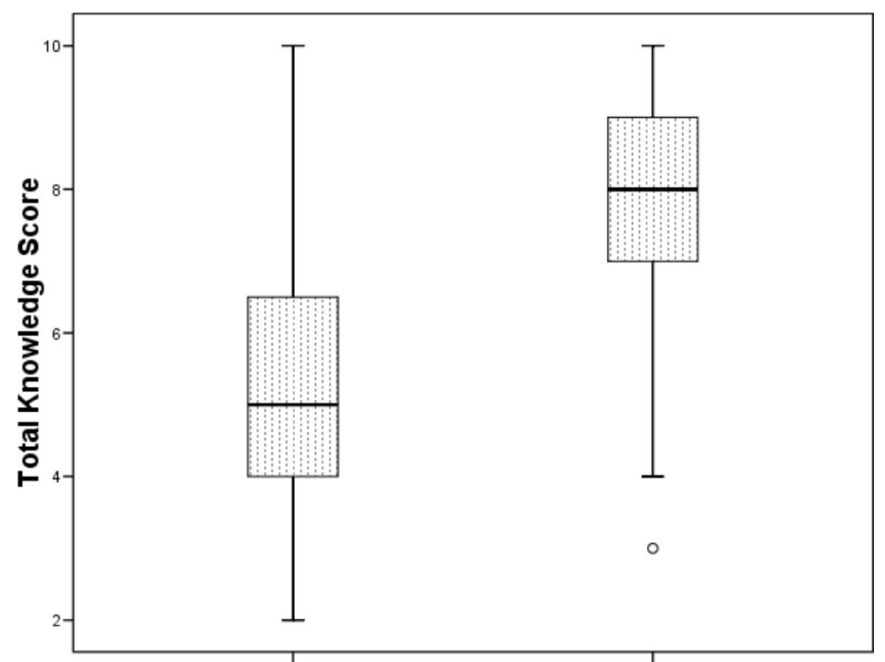

Pre-training

Post-training

Figure 1 Box plot depicting improvement in knowledge score.

Further, NICU nurses fared better in almost all aspects of intravenous cannulation.

Evidence from the same training centre revealed that low-fidelity simulation was as effective as high-fidelity simulation in training neonatal resuscitation to undergraduate medical students. ${ }^{13}$

It is well known that more experience and high selfrated competence is associated with better skills in intravenous cannulation. ${ }^{14}$ NICU nurses had better performance levels in this study, which was on a neonatal manikin, confirming these previous findings. This could be explained by factors such as more patient exposure and regular training of nurses by fellows and residents, blame-free culture and policy of not transferring to other wards leading to low attrition rate.

Currently, the NICU is well equipped and a blame-free culture is instilled among the NICU staff. Further, as a policy decision, NICU nurses are not transferred to the other wards for past 8-9 years and get satisfactory rewards resulting in low attrition rate. The unit also conducts a fellowship programme for neonatology and one of the components for residents is regular training of nurses. They also have more patient exposure and repeated need to insert intravenous cannulas in neonates. The nurses have opportunity to participate in more academic training programmes as compared with others in the institute as the physician leaders of the NICU are involved in many regional and national learning programmes.

The mean (SD) scores do provide useful information on measuring change but it does not provide enough information on attainment of acceptable level. Identifying and incorporating critical steps are crucial for comprehensive analysis of impact of any educational intervention involving assessment of skills. These steps can be given greater attention during training.

Nursing education in India has a generalised approach with lack of specialisation even at major centres; learning on the job in respective department/hospital being
Table 2 Pretraining performance of nurses

\begin{tabular}{|c|c|c|}
\hline Nurses' characteristics & $\begin{array}{l}\text { Knowledge } \\
\text { score, mean (SD) }\end{array}$ & $\begin{array}{l}\text { Skills, n (\%) } \\
\text { correct }\end{array}$ \\
\hline \multicolumn{3}{|l|}{ Ward posted } \\
\hline \multicolumn{3}{|l|}{ Paediatric wards } \\
\hline $\begin{array}{l}\text { Neonatal intensive } \\
\text { care unit }\end{array}$ & $5.82(1.40)$ & $16(73)$ \\
\hline $\begin{array}{l}\text { Paediatric intensive } \\
\text { care unit }\end{array}$ & $5.11(1.05)$ & $4(44)$ \\
\hline Paediatric ward & $5.87(0.99)$ & $4(50)$ \\
\hline $\begin{array}{l}\text { Cardiac intensive care } \\
\text { unit }\end{array}$ & $4.67(1.21)$ & $0(0)$ \\
\hline Gynaecology ward & $5.29(2.29)$ & $5(29)$ \\
\hline Privilege gold & $6.00(0.76)$ & $4(50)$ \\
\hline Special bed unit & $3.44(1.51)$ & $3(33)$ \\
\hline \multicolumn{3}{|l|}{ Education } \\
\hline $\begin{array}{l}\text { General nursing and } \\
\text { midwifery }\end{array}$ & $5.20(1.79)$ & $27(44)$ \\
\hline $\begin{array}{l}\text { Diploma-general } \\
\text { nursing and midwifery }\end{array}$ & $5.71(1.11)$ & $3(43)$ \\
\hline $\begin{array}{l}\text { Registered nurse } \\
\text { registered midwife }\end{array}$ & $5.83(1.17)$ & $5(83)$ \\
\hline $\begin{array}{l}\text { Auxiliary nurse } \\
\text { midwifery }\end{array}$ & $5.50(0.58)$ & $1(25)$ \\
\hline BSc (Nursing) & Not applicable & $0(0.0)$ \\
\hline \multicolumn{3}{|l|}{ Appointment type } \\
\hline Contractual & $5.28(1.66)$ & $27(42)$ \\
\hline Permanent & $5.33(1.68)$ & $9(60)$ \\
\hline \multicolumn{3}{|l|}{ Experience } \\
\hline $0-5$ years & $5.16(1.80)$ & $16(37)$ \\
\hline $6-10$ years & $5.13(1.30)$ & $9(60)$ \\
\hline $11-15$ years & $5.33(1.41)$ & $5(56)$ \\
\hline 16 years or more & $5.92(1.68)$ & $6(50)$ \\
\hline
\end{tabular}

common. Learning on the job may have variable exposure to procedure and cannot guarantee satisfactory skills for intravenous cannulation in children. Simulation technique on high/low-fidelity manikins is proven beneficial in the case of adult simulation. Our study addresses the lack of studies in the newborn/paediatric populations.

Being skilled in various parameters such as proper technique of insertion and fixation, appropriate cannula selection, adequate monitoring and maintenance has significant impact beyond the immediate clinical scenario. ${ }^{15}$ A study, which evaluated the effects of various equipment used for venepuncture on the antecubital vein of an adult manikin, found that simulation education was beneficial in improving intravenous cannulation skills of experienced nurses. ${ }^{16}$ Similarly, in medical students, a randomised controlled trial involving undergraduate students revealed that intravenous cannulation-related skills acquired in a skills laboratory is superior to bedside 
Table 3 Comparison of knowledge scores before and after the training programme

\begin{tabular}{|c|c|c|}
\hline Questions & of correct answers & answers \\
\hline When we use intravenous therapy in children? & $70(87)$ & $74(99)$ \\
\hline When we should not give intravenous therapy? & $19(24)$ & $51(68)$ \\
\hline Check list before administration contains & $56(71)$ & $66(88)$ \\
\hline Mention toddler age group & $50(63)$ & $68(91)$ \\
\hline Ideal solution for flushing & $61(77)$ & $61(81)$ \\
\hline $\begin{array}{l}\text { Intravenous cannula for neonates should be without injection port } \\
\text { (True/False) }\end{array}$ & $30(38)$ & $55(73)$ \\
\hline $\begin{array}{l}\text { Total parenteral nutrition (TPN) will be administered via a dedicated } \\
\text { lumen of a central venous catheter. TPN may not be administered } \\
\text { peripherally (True/False) }\end{array}$ & $27(34)$ & $36(48)$ \\
\hline Tick intravenous therapy related complications & $29(37)$ & $43(57)$ \\
\hline To prevent infiltration & $61(77)$ & $65(87)$ \\
\hline Inspection of intravenous line after every ___ hour & $15(19)$ & $45(60)$ \\
\hline Mean (SD) total score out of $10^{*}$ & $5.32(1.57)$ & $7.52(1.58)$ \\
\hline
\end{tabular}

*Mean (SD) was calculated for 75 participants who completed both the assessments.

teaching, which enabled students to perform intravenous cannulation more professionally. ${ }^{17}$ In a prospective evaluation of success rates in intravenous cannulation in children, it was found that $53 \%$ successfully cannulated on the first attempt, $67 \%$ within two attempts and $91 \%$ within four attempts. ${ }^{18}$ In a randomised controlled trial comparing manikins with actual practice on one another in nursing students, there was evidence of equivalence between the methods with the risk of harm being lesser with the use of manikins. ${ }^{19}$

This study showed improvement in knowledge as well as skills among nurses from all departments irrespective of patient exposure/years of experience. The current study does not show actual improvement of skill on real

Table 4 Comparison of intravenous cannulation skill before and after the training programme

\section{Steps}

Ensures the equipment availability required for the procedure

Checks identity of patient wrist band (hospital no.)

Assistant applies proximal pressure*

Does hand hygiene*

Cleans area with antiseptic

Appropriate intravenous cannula $30^{\circ}$ to skin

Proper insertion of catheter in vein (flash back of blood in cannula seen $)^{\star}$

Completes successful insertion of cannula in 1-2 attempts (ie, gets blood on aspiration in syringe)*

\begin{tabular}{llc} 
Cleans blood spillage & $17(22)$ & $37(49)$ \\
\hline Assistant removes proximal pressure & $77(98)$ & $72(96)$ \\
\hline Attaches blocker & $76(96)$ & $75(100)$ \\
Removes gloves & $68(86)$ & $69(92)$ \\
\hline Fixes dressing properly & $77(98)$ & $75(100)$ \\
Participants exhibiting satisfactory skill & $36(48.0)$ & $69(92.0)$ \\
Mean (SD) total score out of 10† & $7.91(1.11)$ & $9.22(0.66)$ \\
\hline
\end{tabular}

*Mean (SD) was calculated for 75 participants who completed both the assessments.

†ldentified as critical steps. of correct performance performance

\begin{tabular}{cl}
$53(67)$ & $70(93)$ \\
$13(17)$ & $29(39)$ \\
$79(100)$ & $75(100)$ \\
$64(81)$ & $71(95)$ \\
$43(54)$ & $68(91)$ \\
$27(34)$ & $73(97)$ \\
$71(90)$ & $75(100)$ \\
$58(73)$ & $73(97)$ \\
$17(22)$ & \\
$77(98)$ & $37(49)$ \\
$76(96)$ & $72(96)$ \\
$68(86)$ & $75(100)$ \\
$77(98)$ & $69(92)$ \\
$36(48.0)$ & $75(100)$ \\
$7.91(1.11)$ & $69(92.0)$ \\
\hline 5
\end{tabular}

Post-training $(\mathrm{n}=75)$,

Pretraining $(\mathrm{n}=79), \mathrm{n}(\%) \mathrm{n}(\%)$ of correct 
patients in terms of number of attempts required for successful cannulation. This can, however, be addressed in the future through technics such as video audits.

The main strength of the study lies in an organised effort to develop and test a contextual training module for intravenous cannulation in paediatric nurses with a reasonable scientific rigour. However, there were some practical issues that should be considered before a general standardised module could be developed in future. The limitation being retention of skills over longer periods of time was not evaluated-but it is likely that skills are being retained as intravenous cannulation is a frequent practice in most of the areas of hospital. Another limitation is the post-training evaluation on real patients, which probably would have assessed the respective skills in reallife situations.

However, improvement in skills as documented on training on manikin in controlled environment may not result in improvement in real-life situations like stressful/intensive care unit environments. This could be due to variable factors including more patient load and availability of staff per patient, patient's clinical severity, patient temperament, personnel available to immobilise the child, etc.

Training using manikin showed improvement in post-training score of intravenous cannulation skill of paediatric nurses; however, this finding needs further confirmation by a randomised control trial, as our study does not have a control group. The module can be refined and tested further to evolve it as a standard module to train and evaluate intravenous cannulation skills of paediatric nurses at various levels (education, pre-employment, reinforcement, etc).

Acknowledgements The authors thank Apurva Chapla for assistance in conducting the study and Amee Amin and Maunil Bhatt for language check.

Contributors VAM and DVP contributed to the design of the study, data acquisition, data analysis and writing the manuscript. BVS contributed to the design and plan of analysis of the study, data analysis, writing the manuscript, intellectual contribution and final approval of this manuscript. SMN contributed to the design and planning of the study, data analysis, revision of the manuscript for important intellectual content and final approval of this manuscript. AGP contributed to the design of study, plan of analysis, data analysis, writing the manuscript and final approval of the same. ASN helped in designing the planning strategy, data analysis, wrote the manuscript and approved the final manuscript.

Competing interests None declared.

Ethics approval Instituitonal Ethics Committee of HM Patel Center for Medcal Education.

Provenance and peer review Not commissioned; externally peer reviewed.

Data sharing statement Data if required will be available from Dr Somashekhar Nimbalkar.
Open Access This is an Open Access article distributed in accordance with the Creative Commons Attribution Non Commercial (CC BY-NC 4.0) license, which permits others to distribute, remix, adapt, build upon this work non-commercially, and license their derivative works on different terms, provided the original work is properly cited and the use is non-commercial. See: http://creativecommons.org/ licenses/by-nc/4.0/

(c) Article author(s) (or their employer(s) unless otherwise stated in the text of the article) 2017. All rights reserved. No commercial use is permitted unless otherwise expressly granted.

\section{REFERENCES}

1. Pettit J. Assessment of the infant with a peripheral intravenous device. Adv Neonatal Care 2003;3:230-40.

2. Willis J. I.V. therapy: an expanding role with implications for education. Nurs Times 1999;95:48-9.

3. Frey AM. Success rates for peripheral iv insertion in a children's hospital. J Infusion Nursing 1998;21:160-5.

4. Wilkinson R. Nurses' concerns about i.v. therapy and devices. Nurs Stand 1996;10:35-7.

5. Clarke HF. Using research to make a difference in clinical nursing practice. Int Pedi Conf; Canada 1995:1-4.

6. Keenlyside D. Every little detail counts. Infection control in i.v. therapy. Prof Nurse 1992;7:226-32.

7. Lundgren A, Wahren LK. Effect of education on evidence-based care and handling of peripheral intravenous lines. $J$ Clin Nurs 1999;8:577-85.

8. Courtenay M. In: Downie G, Mackenzie J, Williams A, eds. Pharmacology and medicines management for nurses. Edinburgh: Churchill Livingstone, 2003

9. Hadaway LC. What you can do to decrease catheter-related infections. Nursing 2002;32:46-8.

10. Kneebone R, Nestel D, Yadollahi F, et al. Assessing procedural skills in context: exploring the feasibility of an Integrated Procedural Performance Instrument (IPPI). Med Educ 2006:40:1105-14.

11. The Nursing Council of New Zealand. Principals for peripheral intravenous cannula insertion and administration of primary care specified intravenous therapies for registered nurses. Appendix B: One point lesson-IV Cannulation 8,9 https://www.ccdhb.org.nz/ working-with-us/nursing-and-midwifery-workforce-development/ primary-and-community-nursing/principals-of-intravenouscannulation-for-registered-nurses-in-primary-care-final.pdf (accessed 20 Aug 2017).

12. OSCE Skills. Intravenous cannulation (IV). http://www.osceskills. com/e-learning/subjects/intravenous-cannulation/ (accessed on 17 Aug 2017).

13. Nimbalkar A, Patel D, Kungwani A, et al. Randomized control trial of high fidelity vs low fidelity simulation for training undergraduate students in neonatal resuscitation. BMC Res Notes 2015;8:636.

14. Larsen P, Eldridge D, Brinkley J, et al. Pediatric peripheral intravenous access: does nursing experience and competence really make a difference? J Infus Nurs 2010;33:226-35

15. Goff DA, Larsen P, Brinkley J, et al. Resource utilization and cost of inserting peripheral intravenous catheters in hospitalized children. Hosp Pediatr 2013;3:185-91.

16. Fujii C. A comparison of the effects of different equipment used for venipuncture to aid in promoting more effective simulation education. J Blood Disord Transfus 2014;05:228.

17. Lund F, Schultz J-H, Maatouk I, et al. Effectiveness of IV cannulation skills laboratory training and its transfer into clinical practice: a randomized, controlled trial. PLoS One 2012;7:e32831.

18. Lininger RA. Pediatric peripheral i.v. insertion success rates. Pediatr Nurs 2003;29:351-4.

19. Jones RS, Simmons A, Boykin GL, et al. Measuring intravenous cannulation skills of practical nursing students using rubber mannequin intravenous training arms. Mil Med 2014;179:1361-7. 